\title{
Recent advancements in the understanding of tetraspanin functions
}

\author{
Luise Florin ${ }^{1}\left[\right.$. Charlotte M. de Winde ${ }^{2}$ (])
}

Published online: 23 July 2020

(c) The Author(s) 2020

The spatiotemporal coordination of transmembrane proteins plays an important role in an exceptionally wide range of cellular activities, including in all steps of pathogen infection as well as immunological processes. Tetraspanin proteins are the master organizers of membrane proteins, and are therefore involved in physiological and pathophysiological processes, as presented in this special issue "Tetraspanins in Infection and Immunity". These transmembrane proteins span the membrane four times and form extended subdomains by means of their strong tendency to associate laterally with one another and with different classes of proteins, such as cell surface receptors, immunoglobulins, adhesion and signalling molecules, and proteases [1]. As such, they anchor specific proteins to one site on the cell membrane forming microclusters that then further organize into larger assemblies, the so-called tetraspanin-enriched microdomains. These microdomains enable membrane dynamics, like endocytosis, recycling, exocytosis, cell motility, fusion and signalling. The role of tetraspanins in cell fusion, for example, is described in mammalian reproductive processes and development [2].

Because of their involvement in a wide range of cellular processes, tetraspanins are exploited by many pathogens such as viruses and bacteria during their entry and egress. In addition, dysregulation of normal tetraspanin function leads to diseases like cancer, diabetes, Alzheimer's and autoimmune reactions [3, 4]. This, coupled with their easy accessibility as membrane proteins, means that tetraspanins

This editorial is part of the Special Issue on Tetraspanins in Infection and Immunity.

Luise Florin

lflorin@uni-mainz.de

1 Institute for Virology and Research Center for Immunotherapy (FZI), University Medical Center of the Johannes Gutenberg-University Mainz, Obere Zahlbacher Strasse 67, 55131 Mainz, Germany

2 Stromal Immunology Group, MRC Laboratory for Molecular Cell Biology, University College London, Gower Street, London WC1E 6BT, UK have a huge potential to serve as therapeutic targets for the development of new treatments in cancer, hematological malignancies and infectious diseases [5-8].

In recent years, it became apparent that tetraspanins define entry sites of hepatitis $\mathrm{C}$ virus (HCV), human papilloma virus (HPV), coronavirus, influenza A virus, and human immunodeficiency virus by organizing receptors and other components into viral entry platforms $[9,10]$. In this issue, five research studies deepen our understanding of the role of tetraspanins in bacterial and viral infections. Super-resolution and confocal imaging analyses suggest that contact of HPV16 particles with the cell surface triggers the formation of large three-dimensional tetraspanin architectures that contain at least two different tetraspanins, CD151 and CD63, and are connected to filamentous actin [11]. In the same virus and cell system, additional tetraspanins like CD9 not necessarily support infection, but act as negative regulators of the invasion process [12]. In this study, comparative analyses using CD9 low- or high-expressing cells suggest that a specific tetraspanin expression optimum promotes the entry process of the pathogen. The inhibitory role of CD9 and CD81 during pathogen infection is also shown by Elgawidi and colleagues [13]. Burkholderia thailandensis is able to induce the formation of multinucleated giant cells where these tetrapanins are involved. The authors used tetraspanin antibodies and recombinant proteins corresponding to the large extracellular domain of the tetraspanins to modulate their function. They show that antibodies against CD9 and CD81 enhanced the cell-cell fusion process induced by the bacterium whereas recombinant tetraspanin proteins acted in an inhibitory way.

In addition to their function in plasma membrane processes, tetraspanins also regulate intracellular processes by the modulation of signalling pathways [1]. Benayas and colleagues show that the loss of CD81 on herpes simplex virus type-1 infected cells compromised replication of viral DNA and formation of new infectious particles [14]. The relevance of tetraspanins in naturally occurring infections and their outcome is additionally supported by the study of Alberione et al. [15]. They provide evidence that genetic host-variation 
contributes to inter-individual differences in $\mathrm{HCV}$ infection and outcome.

Tetraspanins are involved in many aspects of immunity, and as such play a pivotal role in establishing an effective immune response [16-18]. Further overview articles in this special issue highlight that tetraspanins control different stages of the migration of dendritic cells, which engulf and present antigens to initiate an immune response, from the site of infection to the lymph node [19]. On mast cells, important in antiviral responses and hyperactive in patients with allergies, tetraspanins control release of intracellular granules with immunomodulatory compounds by membrane remodelling [20]. Two tetraspanins, CD37 and CD53, are exclusively expressed on immune cells [21]. The role of CD37 has been studied extensively in the past two decades, but studies investigating the function of CD53 have only emerged in recent years. In this issue, Dunlock has provided a detailed review on the multifunctional role of CD53 in the immune system, controlling immune cell adhesion and migration, and intracellular signalling pathways [22].

New functional roles for tetraspanins are continuously being discovered, and possibilities for targeting tetraspanins in diseases are emerging. McLaughlin and colleagues review an important role for Tspan7 in the autoimmune response in type 1 diabetes, and propose targeting Tspan7 as a promising strategy to prevent disease [4]. Furthermore, Gavin and colleagues present in this issue Tspan 18 as a new regulator of calcium signalling in activated endothelial cells, thereby controlling thrombo-inflammation in acute organ damage upon ischaemic stroke and venous thrombosis [23]. Targeting Tspan 18 may be a better potential therapeutic strategy to interfere with endothelial function than targeting Orai1 which is widely expressed on a diverse range of cell types.

Tetraspanin biology is intensively studied since the discovery of this protein family in the mid 1980s, and has developed into a hot topic with several interfaces between structural molecular biology and a variety of diseases. New imaging technologies, such as superresolution microscopy or simulations of molecular dynamics, in combination with functional analysis now enable scientists to understand key mechanisms in the formation of tetraspanin-enriched microdomains and tetraspanin-regulated processes. This will significantly contribute to the discovery of promising tetraspanin targets to treat infections, immunological pathologies, and other diseases. The aim of this special issue is to update the reader in the latest findings concerning the function of tetraspanins in different physiological and pathological situations, focussing on infection and immunity.

Luise Florin

Charlotte M. de Winde

MMIM Guest Editors
Acknowledgements Open Access funding provided by Projekt DEAL.

Open Access This article is licensed under a Creative Commons Attribution 4.0 International License, which permits use, sharing, adaptation, distribution and reproduction in any medium or format, as long as you give appropriate credit to the original author(s) and the source, provide a link to the Creative Commons licence, and indicate if changes were made. The images or other third party material in this article are included in the article's Creative Commons licence, unless indicated otherwise in a credit line to the material. If material is not included in the article's Creative Commons licence and your intended use is not permitted by statutory regulation or exceeds the permitted use, you will need to obtain permission directly from the copyright holder. To view a copy of this licence, visit http://creativecommons.org/licenses/by/4.0/.

\section{References}

1. Kummer D, Steinbacher T, Schwietzer MF et al (2020) Tetraspanins: integrating cell surface receptors to functional microdomains in homeostasis and disease. Med Microbiol Immunol. https://doi. org/10.1007/s00430-020-00673-3

2. Jankovičová J, Neuerová Z, Sečová P et al (2020) Tetraspanins in mammalian reproduction: spermatozoa, oocytes and embryos. Med Microbiol Immunol. https://doi.org/10.1007/s00430-02000676-0

3. Perot BP, Ménager MM (2020) Tetraspanin 7 and its closest paralog tetraspanin 6: membrane organizers with key functions in brain development, viral infection, innate immunity, diabetes and cancer. Med Microbiol Immunol. https://doi.org/10.1007/s0043 0-020-00681-3

4. McLaughlin KA, Tombs MA, Christie MR (2020) Autoimmunity to tetraspanin-7 in type 1 diabetes. Med Microbiol Immunol. https ://doi.org/10.1007/s00430-020-00674-2

5. Beckwith KA, Byrd JC, Muthusamy N (2015) Tetraspanins as therapeutic targets in hematological malignancy: a concise review. Front Physiol 6:91. https://doi.org/10.3389/fphys.2015.00091

6. Fast LA, Mikuličić S, Fritzen A et al (2018) Inhibition of tetraspanin functions impairs human papillomavirus and cytomegalovirus infections. Int J Mol Sci 19:3007. https://doi.org/10.3390/ijms1 9103007

7. Vences-Catalán F, Kuo C-C, Rajapaksa R et al (2019) CD81 is a novel immunotherapeutic target for B cell lymphoma. J ExpMed 216:1497-1508. https://doi.org/10.1084/jem.20190186

8. Heo K, Lee S (2020) TSPAN8 as a novel emerging therapeutic target in cancer for monoclonal antibody therapy. Biomolecules 10:388. https://doi.org/10.3390/biom10030388

9. Florin L, Lang T (2018) Tetraspanin assemblies in virus infection. Front Immunol 9:1140. https://doi.org/10.3389/fimmu .2018.01140

10. Hantak MP, Qing E, Earnest JT, Gallagher T (2019) Tetraspanins: architects of viral entry and exit platforms. J Virol 93:674. https:// doi.org/10.1128/JVI.01429-17

11. Finke J, Hitschler L, Boller K et al (2020) HPV caught in the tetraspanin web? Med Microbiol Immunol. https://doi.org/10.1007/ s00430-020-00683-1

12. Mikuličić S, Fritzen A, Scheffer K et al (2020) Tetraspanin CD9 affects HPV16 infection by modulating ADAM17 activity and the ERK signalling pathway. Med Microbiol Immunol. https://doi. org/10.1007/s00430-020-00671-5

13. Elgawidi A, Mohsin MI, Ali F et al (2020) A role for tetraspanin proteins in regulating fusion induced by Burkholderia thailandensis. Med Microbiol Immunol. https://doi.org/10.1007/s0043 0-020-00670-6 
14. Benayas B, Sastre I, López-Martín S et al (2020) Tetraspanin CD81 regulates HSV-1 infection. Med Microbiol Immunol. https ://doi.org/10.1007/s00430-020-00684-0

15. Alberione MP, Moeller R, Kirui J et al (2020) Single-nucleotide variants in human CD81 influence hepatitis $C$ virus infection of hepatoma cells. Med Microbiol Immunol. https://doi.org/10.1007/ s00430-020-00675-1

16. Saiz ML, Rocha-Perugini V, Sánchez-Madrid F (2018) Tetraspanins as organizers of antigen-presenting cell function. Front Immunol 9:1074. https://doi.org/10.3389/fimmu.2018.01074

17. Zou F, Wang X, Han X et al (2018) Expression and function of tetraspanins and their interacting partners in B cells. Front Immunol 9:1606. https://doi.org/10.3389/fimmu.2018.01606

18. Yeung L, Hickey MJ, Wright MD (2018) The many and varied roles of tetraspanins in immune cell recruitment and migration. Front Immunol 9:1644. https://doi.org/10.3389/fimmu .2018 .01644

19. de Winde CM, Munday C, Acton SE (2020) Molecular mechanisms of dendritic cell migration in immunity and cancer. Med Microbiol Immunol. https://doi.org/10.1007/s00430-020-00680-4
20. Orinska Z, Hagemann PM, Halova I, Draber P (2020) Tetraspanins in the regulation of mast cell function. Med Microbiol Immunol. https://doi.org/10.1007/s00430-020-00679-x

21. de Winde CM, Zuidscherwoude M, Vasaturo A et al (2015) Multispectral imaging reveals the tissue distribution of tetraspanins in human lymphoid organs. Histochem Cell Biol 144:133-146. https ://doi.org/10.1007/s00418-015-1326-2

22. Dunlock VE (2020) Tetraspanin CD53: an overlooked regulator of immune cell function. Med Microbiol Immunol. https://doi. org/10.1007/s00430-020-00677-z

23. Gavin RL, Koo CZ, Tomlinson MG (2020) Tspan18 is a novel regulator of thrombo-inflammation. Med Microbiol Immunol. https://doi.org/10.1007/s00430-020-00678-y

Publisher's Note Springer Nature remains neutral with regard to jurisdictional claims in published maps and institutional affiliations. 